\title{
Video Profil Pondok Modern Az-Zahra Al Gontory Sebagai Media Promosi di Platform Sosial Media Facebook Menggunakan Facebook Ads
}

\author{
Retno Waluyo', Argiyan Dwi Pritama², Lutfi Nugroho ${ }^{3}$ \\ ${ }^{1,2}$ Program Studi Sistem Informasi, Fakultas Ilmu Komputer, Universitas Amikom Purwokerto \\ ${ }^{3}$ Program Studi Informatika, Fakultas Ilmu Komputer, Universitas Amikom Purwokerto \\ waluyo@amikompurwokerto.ac.id,
}

\begin{abstract}
Abstrak
Pesantren menjadi bagian dari sistem pendidikan nasional yang menjadi mitra institusi pemerintah secara bersama-sama meningkatkan kualitas pendidikan dan landasan karakter bangsa. Pondok Pesantren Az-Zahra Al Gontory mendidik kader-kader ummat yang dibangun atas dasar nilai Iman, Islam, dan Ihsan secara Kaafah. Saat ini pondok pesantren cenderung dipandang sebelah mata oleh masyarakat maupun calon santri dikarenakan kurangnya informasi dan edukasi. Selama ini penyebaran informasi hanya menggunakan banner sehingga jangkauan informasi tidak luas. Oleh karena itu diperlukan media lain yang dapat digunakan sebagai promosi dengan jangkauan yang luas. Tujuan penelitian in akan membuat Video Profil Sebagai Sarana Promosi Pondok Modern Pesantren Modern Az-Zahra Al Gontory di Sosial Media dengan teknik sinematografi dengan tahapan pra prodiksi, produksi dan pasca produksi. Hasil penelitian ini berupa video profil yang digunakan sebagai media promosi di sosial media sehingga jangkauan informasi kepada masyarakat lebih luas dan peningkatan pengetahuan masyarakat mengenai pondok Modern AzZahra Al Gontory.
\end{abstract}

Kata Kunci - Video Profil, Pondok Pesantren, Sosial Media.

\begin{abstract}
Islamic boarding schools are part of the national education system, partnering with government institutions to jointly improve the quality of education and the foundation of national character. Pondok Pesantren Az-Zahra Al Gontory educates ummat cadres who are built on the basis of the values of Faith, Islam and Ihsan in Kaafah. Currently, Islamic boarding schools tend to be underestimated by the public and prospective students due to a lack of information and education. So far, information dissemination has only used banners so that the reach of information is not wide. Therefore we need other media that can be used as promotion with a wide reach. The purpose of this research is to make a video profile as a means of promoting the Az-Zahra Al Gontory Modern Islamic Boarding School on social media with cinematographic techniques with pre-production, production and post-production stages. The results of this study are in the form of a video profile that is used as a promotional media in social media so that the reach of information to the public is wider and increases public knowledge about the Modern Az-Zahra Al Gontory cottage.
\end{abstract}

Keywords - Video Profile, Pondok Pesantren, Social Media 


\section{PENDAHULUAN}

Pondok pesantren muncul sekitar 300-400 tahun yang lalu dan menjangkau sebagian besar umat muslim sehingga menjadi pelopor lembaga pendidikan islam di indonesia (Syafe'i, 2017). pondok pesantren sendiri memiliki kelebihan dibandingkan lembaga pendidikan yang lain dimana figur kyai menjadi sosok yang utama, selain itu pesantren mengajarkan nilai-nilai dalam kehidupan sehari-hari dan nilai-nilai keislaman diantaranya akhlaqul karimah, ukhuwah, gotong royong, ketulusan dan kemandirian (Baharun, 2017).

Saat ini terdapat pesantren yang menjadi bagian dari sistem pendidikan nasional, sehingga fokus pendidikan tidak hanya pada ilmu agama saja namun pengetahuan umum juga diberikan, akan tetapi penerapannya berbeda dengan sekkolah umum biasa, dalam hal ini pelaksanaan pembelajaran dipesantren dilakukan hampir 24 jam setiap harinya (Annisa \& Alfiasari, 2017). berdasarkan UU Sisdiknas Pasal 30 ayat (4) pesantren merupakan bagian pendidikan agama yang menjadi mitra institusi pemerintah secara bersama-sama meningkatkan kualitas pendidikan dan landasan karakter bangsa (Syafe'i, 2017).

Pondok Pesantren Az-Zahra Al Gontory adalah Pondok Pesantren Modern yang terletak di Gunung Tugel, Purwokerto merupakan sebuah Lembaga pendidikan yang mendidik kader-kader ummat yang dibangun atas dasar nilai Iman, Islam, dan Ihsan secara Kaafah. Berawal dari sebuah Majlis Ta'lim Al Istiqomah yang terletak di grumbul Gunung Tugel kemudian pada tahun 2010 didirikanlah sebuah Pondok Pesantren Az-Zahra dan Madrasah Diniyah sebagai lembaga pendidikannya. Sejak awal berdiri pada tahun 2010 hingga saat ini terus melakukan inovasi dalam pendidikan, budaya dan ekonomi guna menciptakan generasi ummat yang bertakwa, militan, dan berpengetahuan luas. Sehingga lulusan yang dihasilkan diharapkan menjadi investasi berharga bagi bangsa, negara, dan Agama. Pendidikan sebagai upaya pembentukan karakter adalah bagian integral dari orientasi pendidikan Islam. Tujuannya adalah membentuk kepribadian seseorang agar berperilaku jujur, baik dan bertanggungjawab, menghormati dan menghargai orang lain, adil, tidak diskriminatif, egaliter, pekerja keras dan karakter- karakter unggul lainnya.

Namun dengan kemajuan teknologi saat ini pondok pesantren cenderung dipandang sebelah mata oleh masyarakat maupun calon santri dikarenakan sistem pendidikan di pondok pesantren dianggap terlalu tradisional atau ketinggalan zaman. Hal ini mengakibatkan kurangnya peminat masyarakat untuk memasukan putra putrinya ke pondok pesantren. Selain itu kurangnya informasi dan edukasi dari pondok Modern Az-Zahra Al Gontory membuat masyarakat tidak begitu mengenal pondok pesantren. Selama ini penyebaran informasi hanya menggunakan banner sehingga jangkauan informasi tidak luas hanya ditempat tertentu saja. Oleh karena itu diperlukan media lain yang dapat digunakan sebagai promosi dengan jangkauan yang luas.

Untuk mempromosikan suatu perusahaan, produk dan potensi daerah dapat menggunakan komunikasi melalui audio dan visual berupa video company profile sehingga promosi lebih efektif (Astuti, 2014). Dengan video company profil akan memberikan atau menampilkan gambaran nyata dari sebuah objek (Apriliani, Hasanah, \& Anas, 2019). Dengan diimplementasikannya video profil prodi Manajemen Informatika proses promosi lebih mudah dan efektif (Permana, Kertiasih, \& Budhayana, 2017). Selain itu Media promosi berupa video company profile PT. PROPAN RAYA Semarang dirasakan bermanfaat dan dibutuhkan sebagai media pendukung informasi dan promosi bagi perusahaan (Haryanto \& Nugroho, 2015). Salah satu teknik yang dapat digunakan dalam pembuatan video yaitu teknik sinematografi. Sinemtografi merupakan 
sebuah teknik dalam pembuatan film atau seni pengambilan sebuah gambar (Mahendra, Trisnadoli, \& Nugroho, 2018).

Dari uraian diatas maka dirumuskan bahwa Pondok Modern Pesantren Az-Zahra Al Gontory membutuhkan media promosi berupa video yang dapat menjangkau lebih luas. Oleh karena itu tujuan penelitian in akan membuat Video Profil Sebagai Sarana Promosi Pondok Modern Pesantren Modern Az-Zahra Al Gontory.

Video merupakan rangkaian dari frame-frame sehingga menggambarkan sebuah objek terlihat sebagai gambar hidup yang diproses melalui lensa proyektor (Arsyad, 2011). Dengan video dapat mempermudah orang untuk menyerap informasi yang diberikan sehingga akan mempengaruhi sikap (Rahman, 2020).

Company Profile merupakan sebuah gambaran profil sebuah perusahaan untuk mempromosikan perusahaan kepada masyarakat atau customer sehingga tertarik kepada produk atau jasa yang disediakan oleh perusahaan dengan informasi yang disajikan melalui website, video ataupun media lainnya (Haryoko, 2012). Company profile dapat digunakan sebagai media informasi dan promosi bagi perusahaan atau lembaga pendidikan (Sunarya, 2013).

Penelitian yang dilakukan (Sunarya, 2017) membuat video profil SMA Negeri 15 kota Tangerang yang digunakan sebagi media promosi dan informasi sehingga penyampaian informasi lebih efektif, jelas, lugas dan komunikatif mudah diterima oleh calon siswa/siswi baru. Kemudian oleh (Purnawati, 2016) menggunakan teknik sinematografi dalam pembuatan video iklan untuk program publikasi potensi daerah kabupaten banyumas. Selain itu penelitian oleh (Fitriyanti and
D. Ambar, 2016) pembuatan video company profile pabrik gula cepiring bermanfaat sebagai media promosi wisata sehingga penyebaran informasi wisata kepada masyarakat dapat menjangkau lebih luas.

\section{METODE}

Untuk mencapai hasil yang baik dalam pembuatan video diperlukan tahapan-tahapan yang saling berkaitan, Tahapan yang digunakan dalam pembuatan video company profile ini menggunakan 3 tahap antara lain (1) Tahap pra produksi, pada tahap ini merupakan sebuah awal dimulainya pembuatan sebuah karya antara lain ide, perencanaan dan perisapan dari konsep membuat video. Adapun tahapan pra produksi ini diawali dari sebuah ide yang dituangkan secara sistematis, lalu dibuatlah sebuah sinopsis, script writting, pembuatan storyboard, pemilihan crew yang dilibatkan pada saat produksi dan melakukan setting peralatan yang dibutuhkan. agar terlaksana dengan lancar semua kegiatan dilaksanakan tepat waktu sesuai time schedule yang sudah dibuat. (2) Tahap Produksi, Dimana pada tahap ini merupakan tahap pengambilan gambar atau shooting. Pada tahap ini kerjasama semua crew yang terlibat dalam pembuatan video ini sangat dibutuhkan, semua crew bekerja sesuai tugas dan tanggung jawabnya. Pada saat shooting seorang sutradara menentukan shoot yang akan diambil, membuat storyline sebagai pegangan dan segala sesuatu yang terjadi saat pengambilan gambar. (3) Tahap Pasca Produksi, Merupakan tahap akhir dari pembuatan sebuah video yang utuh sehingga layak disajikan kepada audience untuk menyampaikan pesan atau informasi. Pada tahap ini dilakukan editing, finishing dan exporting (Abdillah, 2017).

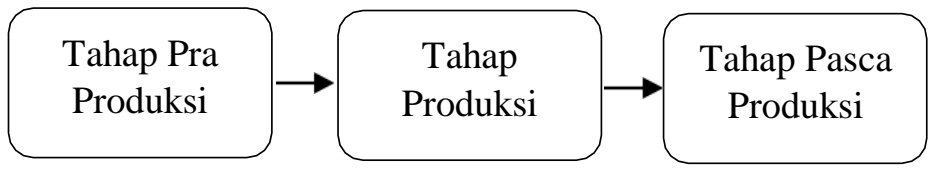

Gambar 1. Tahapan Pembuatan video 


\section{HASIL}

\section{A. Tahap Pra Produksi}

Tahap ini disebut juga sebagai masa persiapan sebelum membuat video profil Pondok Modern Az-Zahra Al Gontory. Pada tahapan ini salah satunya dilakukan pembuatan naskah produksi dengan melibatkan pihak Pondok Modern Az-Zahra Al-Gontory, kemudian dilakukan ekplorasi untuk membuat skenario tahap pertama dan juga menyiapkan segala sesuatu yang dibutuhkan, seperti kamera, tripod, laptop, dan skenario. Pada tahap ini juga dilakukan penelitian terhadap segala hal yang berhubungan dan mempengaruhi video profil yang akan dibuat, seperti melakukan eksplorasi naskah yang mencakup mencari lokasi pengambilan gambar, penyesuaian waktu pengambilan gambar dengan kegiatan sekolah, dan interaksi langsung dengan pengurus Pondok Pesantren Modern Az-Zahra Al Gontory. Tahap yang dilalui pada proses pra produksi dapat dirincikan sebagai berikut :

1) Tahap pertama, penulis datang untuk mengurus perijinan dan meninjau lokasi untuk pembuatan video profil serta berinteraksi secara langsung dengan pengurus Pondok Pesantren Modern Az-Zahra Al Gontory. Selain itu juga dilakukan pengumpulan data yang dibutuhkan untuk pembuatan video profil.

2) Tahap kedua, penulis datang untuk menjelaskan konsep video yang akan dibuat kepada pengurus Pondok Pesantren Modern Az-Zahra Al Gontory dan membuat timeline serta story board pengerjaan video profile, serta melakukan dokumentasi untuk menyiapkan proses produksi video.

Tabel 1. Timeline Video Profil Pondok Modern Az-Zahra

\begin{tabular}{|c|l|l|l|l|l|}
\hline No & Nama Kegiatan & Minggu 1 & Minggu 2 & Minggu 3 & Minggu 4 \\
\hline 1 & $\begin{array}{l}\text { Observasi + } \\
\text { Konsep }\end{array}$ & & & & \\
\hline 2 & $\begin{array}{l}\text { Proses } \\
\text { Pengambilan } \\
\text { Video }\end{array}$ & & & & \\
\hline 4 & Proses Editing & & & & \\
\hline 5 & $\begin{array}{l}\text { Distribusi } \\
\text { Konten Video }\end{array}$ & & & & \\
\hline
\end{tabular}

Dalam dunia videogafi, storyboard berperan sebagai panduan bagi orang-orang yang terlibat didalamnya, mulai dari sutradara, penulis cerita, lighting, kameramen, dan lain-lain sebagainya. Storyboard diibaratkan cetak biru yang dibutuhkan sebagai panduan buat mendirikan sebuah rumah. Kesemuanya itu dimulai dengan storyboard. Untuk melengkapinya, maka diberi kata-kata (dialog) yang diambil dari naskah/script yang diterjemahkan kedalam gambar. 
Tabel 2. Storyboard Video Profil Pondok Modern Az-Zahra

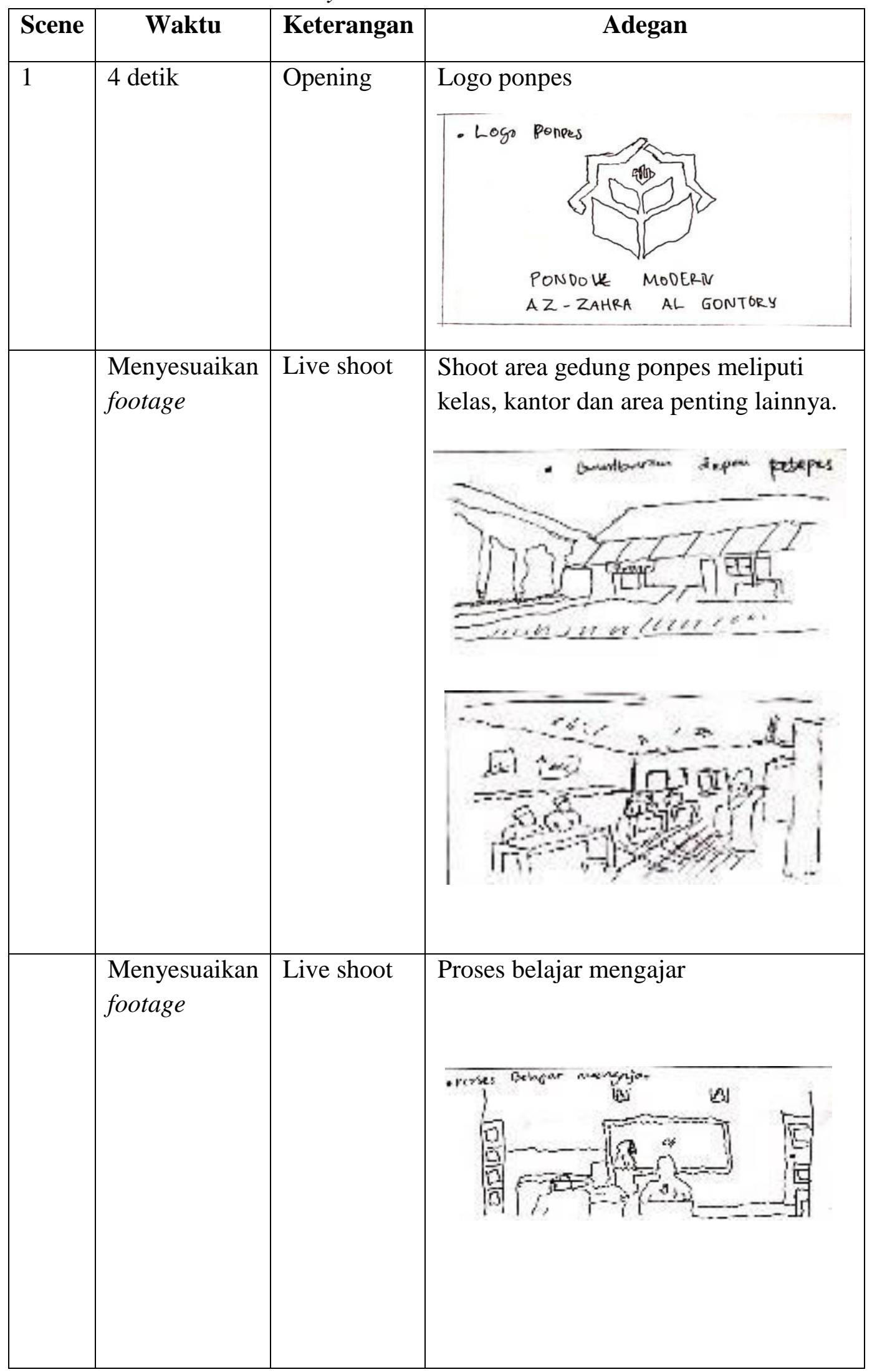




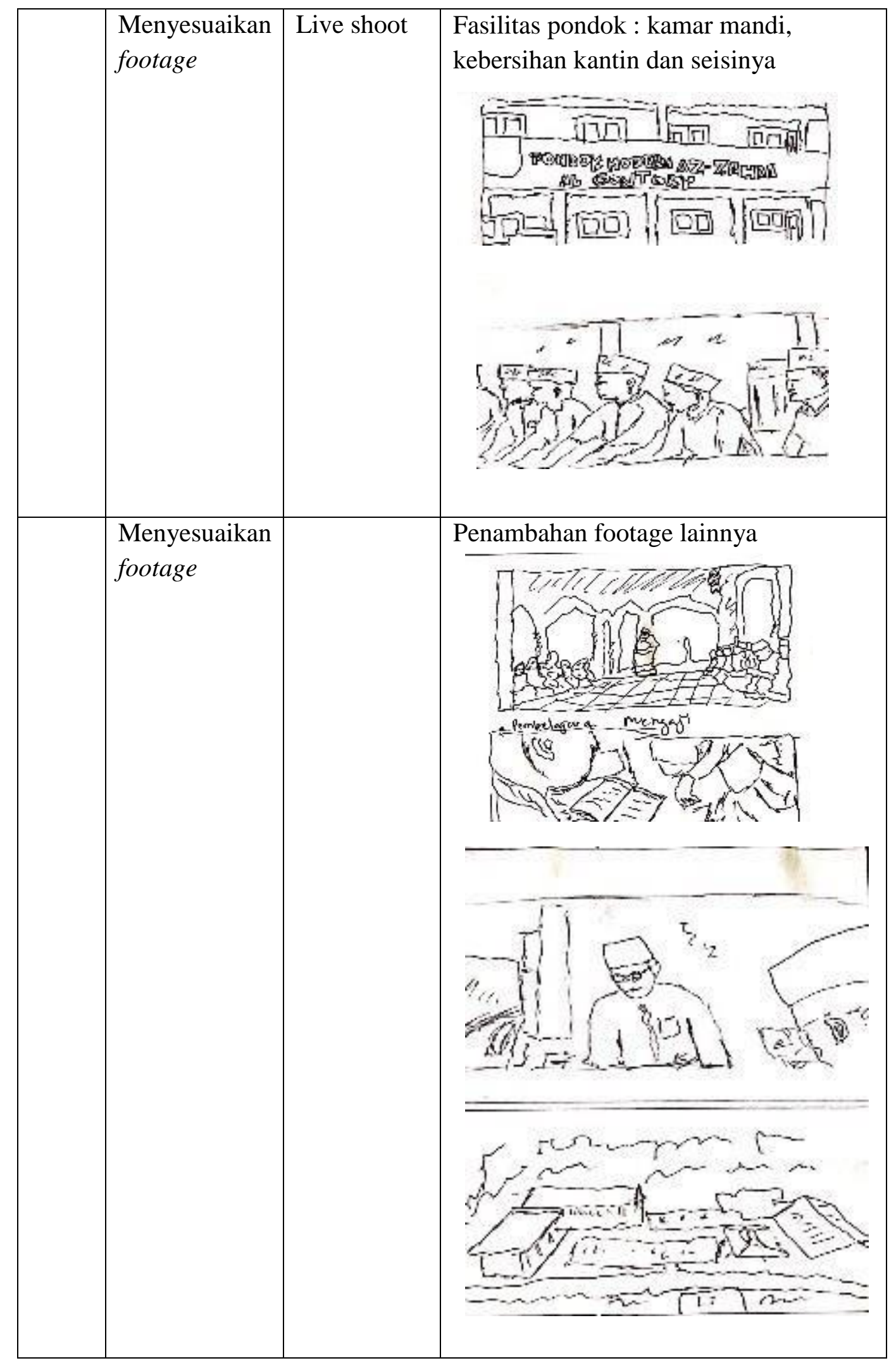




\section{B. Tahap Produksi}

Pengambilan gambar atau yang lebih dikenal dengan proses shoot dapat dilakukan setelah proses pra produksinya selesai dan siap dieksekusi, seperti proses menentukan shoot yang akan diambil, membuat storyline sebagai pegangan dan segala sesuatu yang terjadi saat pengambilan gambar semua haru sudah selesai dan siap dijalankan dengan semua sumberdaya manusia yang ada.

\section{Tahap Pra Produksi}

Tahap pasca produksi berarti tahap setelah pengambilan gambar selesai dilakukan, pada tahapan ini gambar yang sudah diambil akan diolah dan disusun sesuai dengan skenario dan storyboard dan editor akan diarahkan sesuai konsep yang telah ditentukan.

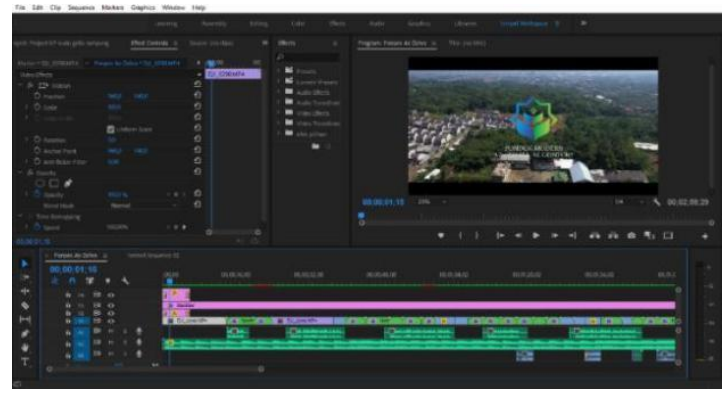

Gambar 1. Proses Editing Video Pondok Pesantren Modern Az-Zahra Al Gontory

Salah satu proses editing yang dilakukan adalah cutting, grading atau pewarnaan, dan menambahan motion graphics menyesuaikan dari keadaan atau alur pada cerita yang telah ditentukan dan dalam prosesnya ini menggunakan software atau perangkat lunak Premiere Pro CC 2018.

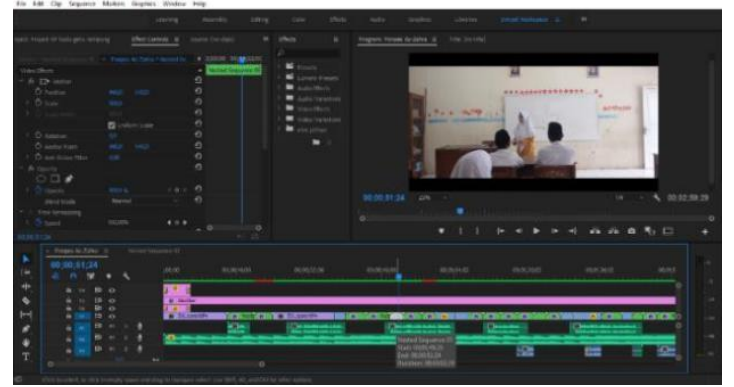

Gambar 2. Proses Editing Video Pondok Pesantren Modern Az-Zahra Al Gontory

Setelah proses Pra Produksi, Produksi, dan Pasca Produksi selesai di lakukan, satu langkah lagi yang tidak kalah penting adalah distribusi konten video profilnya, disini peneliti menggunakan platform sosial media facebook dengan memanfaatkan fitur iklan yang ada, yaitu facebook ads. Proses pengiklanan ini dilakukan di halaman facebook Pondok Pesantren Modern AzZahra Al Gontory.

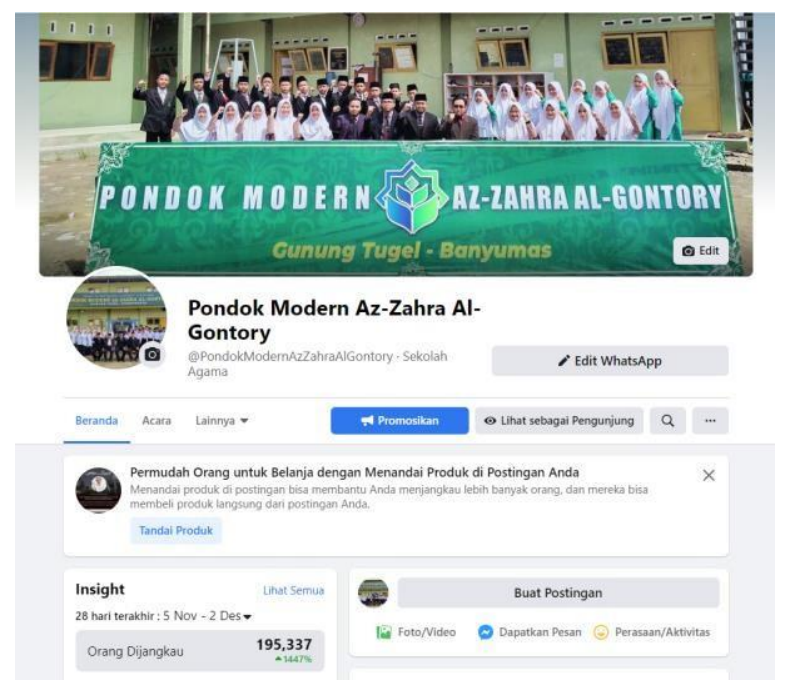

Gambar 3. Facebook FanPage Pondok Pesantren Modern Az-Zahra Al Gontory

Pengiklanan ini dilakukan selama beberapa hari dengan optimasi yang sesuai dengan target pasar atau target calon santi dan orang tua santri 
Proses optimasi facebook ads ini dilakukan dengan berbagai macam pertimbangan yang sudah disebutkan diatas yaitu target pasar dari Pondok Pesantren Modern Az-Zahra Al Gontory itu sendiri sehingga video dapat terdistribusi dengan tepat ke sasaran.

Dalam penelitian in juga dilakukan survei mengenai pemahaman masyarakat terhadap profil Pondok Pesantren Modern Az-Zahra Al Gontory menggunakan kuesioner. Adapun jumlah responden sebanyak 100 orang dengan hasil sebagai berikut:

Dari hasil survei yang telah dilakukan mengenai pengetahuan masyarakat terhadap Profil Pondok Pesantren Modern Az-Zahra Al Gontory yang dilakukan sebelum adanya video profil dan sesudah adanya video profil dapat dijelaskan sebagai berikut, sebelum adanya video profil yang dibuat terdapat $30 \%$ yang sudah tahu Profil Pondok Pesantren Modern Az- Zahra Al Gontory sedangkan 70 $\%$ tidak tahu Profil Pondok Pesantren Modern Az- Zahra Al Gontory. Sedangkan setelah adanya video Profil Pondok Pesantren Modern Az-Zahra Al Gontory terdapat $85 \%$ yang sudah tahu dan $15 \%$ masyarakat masih tidak tahu. Dapat disumpulkan setelah adanya video profil ini terjadi kenaikan sebanyak $55 \%$ orang yang tahu Profil Pondok Pesantren Modern Az-Zahra Al Gontory.

Proses optimasi facebook ads ini dilakukan dengan berbagai macam pertimbangan yang sudah disebutkan diatas yaitu target pasar dari Pondok Pesantren Modern Az-Zahra Al Gontory itu sendiri sehingga video dapat terdistribusi dengan tepat ke sasaran.
Dalam penelitian in juga dilakukan survei mengenai pemahaman masyarakat terhadap profil Pondok Pesantren Modern Az-Zahra Al Gontory menggunakan kuesioner. Adapun jumlah responden sebanyak 100 orang dengan hasil sebagai berikut:

Dari hasil survei yang telah dilakukan mengenai pengetahuan masyarakat terhadap Profil Pondok Pesantren Modern Az-Zahra Al Gontory yang dilakukan sebelum adanya video profil dan sesudah adanya video profil dapat dijelaskan sebagai berikut, sebelum adanya video profil yang dibuat terdapat $30 \%$ yang sudah tahu Profil Pondok Pesantren Modern Az- Zahra Al Gontory sedangkan $70 \%$ tidak tahu Profil Pondok Pesantren Modern AzZahra Al Gontory. Sedangkan setelah adanya video Profil Pondok Pesantren Modern AzZahra Al Gontory terdapat $85 \%$ yang sudah tahu dan $15 \%$ masyarakat masih tidak tahu. Dapat disumpulkan setelah adanya video profil ini terjadi kenaikan sebanyak $55 \%$ orang yang tahu Profil Pondok Pesantren Modern AzZahra Al Gontory.

\section{DAFTAR PUSTAKA}

1. E. Purnawati and Suyanto, "Perancangan Periklanan Multimedia dengan Teknik Sinematografi untuk Program Publikasi (Studi Kasus: Disporabudpar Kabupaten Banyumas)," Telematika, vol. 9, no. 1, pp. 15-26, 2016, doi: 10.35671/telematika.v9i1.407.

2. F. Abdillah, D. Adhiguna, and A. Sevtiana, "Perancangan Video Profile Sebagai Media Promosi Stmik Cic Dengan Tehnik Motion Graphic Menggunakan Perangkat Lunak Komputer Graphic," J. Digit, vol. 7, no. 1, pp. 74-85, 2017. 
3. Fitriyanti and D. Ambar, "Perancangan company profile dan media promosi Pariwisata Pabrik Gula Cepiring Kabupaten Kendal," Arty J. Seni Rupa, vol. 4, no. 1, 2015

4. Baharun, Pengembangan Kurikulum; Teori dan Praktik (Konsep, Prinsip, Pendekatan dan Langkah-langkah Pengembangan Kurikulum PAI. Yogyakarta: CV Cantrik Pustaka., 2017.
5. R. Annisa and Alfiasari, "PENGARUH LINGKUNGAN NON FISIK PESANTREN DAN KECERDASAN EMOSIONAL TERHADAP PENYESUAIAN REMAJA ( KASUS PESANTREN MODERN )," J. Ilmu Kel dan Kons, vol. 10, no. 3, pp. 216-226, 2017.

6. Syafe'i, "Pondok pesantren: Lembaga pendidikan pembentukan karakter," $A l$ Tadzkiyyah J. Pendidik. Islam, vol. 8, no. 1, pp. 61-82, 2017. 
1. 